\title{
The bronchial response to cold air challenge: evidence for different mechanisms in normal and asthmatic subjects
}

\author{
RICHARD W HEATON, ALLAN F HENDERSON, BARRY J GRAY, JOHN F COSTELLO
}

From the Chest Unit, King's College Hospital Medical School, London

ABSTRACT We have investigated possible mechanisms of response to airway cooling by studying the effects of sodium cromoglycate and ipratropium bromide on the changes in airways resistance that followed eucapnic hyperventilation with subfreezing air in a group of 12 patients with mild asthma and 10 normal subjects. We have also studied the period of refractoriness to repeated challenge. Maximum bronchoconstriction was not reduced after the second challenge, but in the asthmatics the one-second forced expiratory volume recovered more rapidly after the second challenge. The response in normal subjects was completely abolished by ipratropium bromide $(\mathrm{p}<0.0005)$ whereas sodium cromoglycate was without effect. In the asthmatics both ipratropium and cromoglycate were effective in attenuating the response $(p<0.005)$. These results suggest that in normal subjects the response to airway cooling is produced predominantly via neural mechanisms, whereas in asthmatics there is an additional mechanism which can be abolished by sodium cromoglycate.

Eucapnic hyperventilation with dry air at subfreezing temperatures has been shown to be a potent stimulus to bronchoconstriction in asthma. ${ }^{1}$ If the stimulus is increased by increasing the level of ventilation then sensitive tests of airway function show that normal individuals will also respond. ${ }^{2}$ Direct measurements have shown that cooling of the distal airways does occur during hyperventilation with room air and to a greater extent with subfreezing air, ${ }^{3}$ and it has been suggested that such airway cooling is the stimulus to the bronchconstriction that occurs with exercise in asthmatics. ${ }^{4}$

Although exercise has long been recognised as a potent trigger of asthma, the mechanism by which wheezing is induced remains unclear. The presence of a refractory period, during which the bronchial response to a repeated exercise challenge is diminished, has been clearly demonstrated ${ }^{56}$ and has led to the suggestion that the release of a preformed stored mediator plays a part. ${ }^{6}$ Recently the appearance in the blood of a neutrophil chemotactic factor has been shown to follow the induction of

Address for reprint requests: Dr RW Heaton, Chest Unit, King's College Hospital Medical School, London SE5 8RX.

Accepted 9 March 1983 asthma by exercise ${ }^{7}$ and this factor appears identical to that released after antigen challenge. ${ }^{8}$ Using cold air as a stimulus, however, other workers have been unable to demonstrate the release of neutrophil chemotactic activity.9 Studies of the effects of sodium cromoglycate and parasympatholytic agents have also shown variable results ${ }^{1011}$ and have led to suggestions that the mechanism of induction of asthma by exercise may differ between individuals.

In the current study we have investigated possible mechanisms of bronchoconstriction after cold air challenge in asthmatic and normal subjects by looking for a period during which they were refractory to the effects of the challenge, and also by studying the effects of sodium cromoglycate and ipratropium bromide on the response.

\section{Methods}

COLD AIR GENERATOR

The apparatus used for generating dry air at subfreezing temperatures is shown in fig 1 . It consists of a heavily insulated PVC cylinder $65 \mathrm{~cm}$ long with an internal diameter of $16 \mathrm{~cm}$, with the cooling coil of a Haake EH51 refrigeration unit fixed inside. Compressed dry air is fed into the cooling chamber via a 200-litre reservoir bag, and this air passes over the 


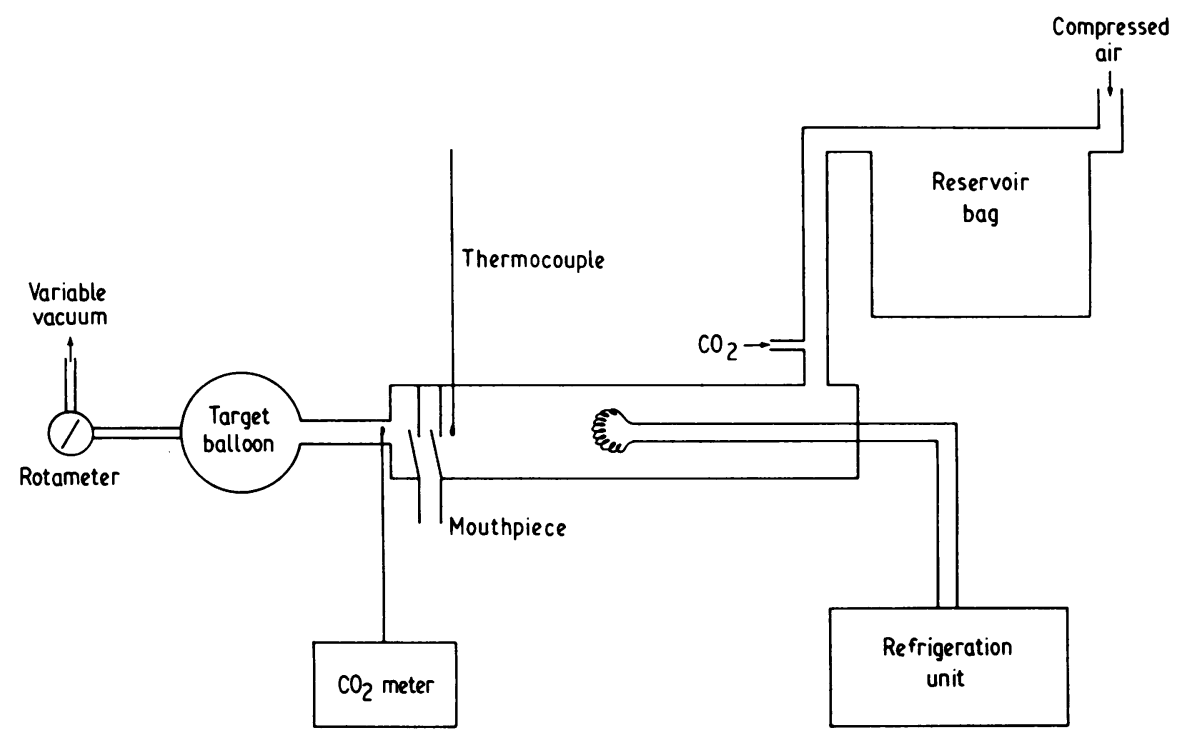

Fig 1 Schematic representation of the apparatus used for delivering a cold air challenge (see text for details). From Heaton ${ }^{22}$, reproduced by courtesy of Breath.

cooling coil before reaching the valve box, which contains two Collins one-way valves to separate the inspired and expired air. Insulation is continued up to the subject's lips to maintain the subfreezing temperatures. Inspired air temperature is measured by a thermocouple located $7 \mathrm{~cm}$ from the subject's mouth. End-tidal carbon dioxide concentration is analysed by a Hartmann and Braun URAS 4 carbon dioxide meter and carbon dioxide is fed into the inspired air to maintain eucapnia. A target balloon in the expiratory circuit is filled before the start of the challenge and the subject's level of ventilation is set by instructing him to keep the target balloon inflated while this is being evacuated by a variable vacuum pump through a rotameter. The degree of cooling of the inspired air is highly reproducible at any flow rate.

\section{PATIENTS}

We studied two groups of patients. A group of 12 asthmatic subjects (five men and seven women: mean aged 24.6 years, range 19-30) was recruited from the asthma clinic at King's College Hospital. All had documented reversibility of airflow obstruction of at least $15 \%$ and were able to discontinue all medications for at least 12 hours before the study. Baseline values of forced expiratory volume in one second $\left(\mathrm{FEV}_{1}\right)$ values were within $30 \%$ of their predicted

Details of the asthmatic subjects studied

\begin{tabular}{|c|c|c|c|c|c|}
\hline $\begin{array}{l}\text { Subject } \\
\text { No }\end{array}$ & Sex & Age & Atopic & $F E V_{1}(l)$ & $\begin{array}{l}\text { Predicted } \\
F E V_{1}(l)\end{array}$ \\
\hline $\begin{array}{r}1 \\
2 \\
3 \\
4 \\
5 \\
6 \\
7 \\
8 \\
9 \\
10 \\
11 \\
12\end{array}$ & $\begin{array}{l}\mathbf{M} \\
\mathbf{F} \\
\mathbf{F} \\
\mathbf{F} \\
\mathbf{M} \\
\mathbf{F} \\
\mathbf{F} \\
\mathbf{F} \\
\mathbf{M} \\
\mathbf{M} \\
\mathbf{F} \\
\mathbf{M}\end{array}$ & $\begin{array}{l}27 \\
24 \\
24 \\
21 \\
24 \\
23 \\
26 \\
29 \\
30 \\
25 \\
24 \\
19\end{array}$ & $\begin{array}{l}\text { Yes } \\
\text { Yes } \\
\text { Yes } \\
\text { Yes } \\
\text { Yes } \\
\text { Yes } \\
\text { No } \\
\text { Yes } \\
\text { Yes } \\
\text { Yes } \\
\text { Yes } \\
\text { Yes }\end{array}$ & $\begin{array}{l}4.80 \\
3.60 \\
3.40 \\
3.00 \\
4.65 \\
2.10 \\
3.30 \\
3.15 \\
3.75 \\
2.65 \\
3.10 \\
3.30\end{array}$ & $\begin{array}{l}4.60 \\
3.40 \\
3.21 \\
3 \cdot 27 \\
4 \cdot 28 \\
2.90 \\
2 \cdot 89 \\
3.16 \\
4 \cdot 60 \\
3 \cdot 82 \\
3 \cdot 30 \\
3 \cdot 80\end{array}$ \\
\hline $\begin{array}{l}\text { Mean } \\
\text { SD }\end{array}$ & & $\begin{array}{c}24 \cdot 6 \\
3.08\end{array}$ & & $\begin{array}{l}3.40 \\
0.75\end{array}$ & $\begin{array}{l}3.60 \\
0.61\end{array}$ \\
\hline
\end{tabular}


normal values, and varied by less than $15 \%$ on all study days. Ten of the 12 had experienced postexertional wheezing. Further details of the asthmatic subjects are given in the table. A group of 10 normal subjects (four men and six women: mean age 22.8 years, range 18-30), with no recent or remote history of asthma and lung function test values within the normal predicted range, was recuited from hospital staff. The mean $\mathrm{FEV}_{1}$ in the normal subjects was $3.82 \pm 0.88(\mathrm{SD}) \mathrm{l}$; the mean predicted $\mathrm{FEV}_{1}$ was $3.59 \pm 0.591$.

All subjects gave informed consent and the protocol was approved by the ethics committee of King's College Hospital.

\section{PROTOCOL}

Subjects attended the laboratory on four occasions, the initial visit being to familiarise them with the apparatus used in the challenge and recording procedures. The study sessions were performed in random order. Responses were recorded as changes in $\mathrm{FEV}_{1}$, recorded on a Vitalograph spirometer, and in specific airways conductance (sGaw), measured in a constant-volume body plethysmograph. Values of sGaw were taken as the mean of five readings at each time interval. $\mathrm{FEV}_{1}$ was recorded in duplicate and the higher value on each occasion taken.

At each session baseline values for $\mathrm{FEV}_{1}$ and sGaw were established. The subjects then received either sodium cromoglycate $40 \mathrm{mg}$ by Spinhaler or ipratropium bromide $40 \mu \mathrm{g}$ by metered-dose aerosol, administered by an investigator who took no further part in the study, or no treatment. The observer making the recordings and administering the challenge was unaware of the treatment given. Fifteen minutes later $\mathrm{FEV}_{1}$ and $\mathrm{sGaw}$ were again determined and the cold air challenge was given. Measurements were repeated at 5, 10, and 20 minutes after the end of the challenge. Cold air was administered for three minutes in all cases. Normal subjects were required to breathe at $80 \%$ of their maximal breathing capacity, calculated as $30 \times \mathrm{FEV}_{1}$ per minute, ${ }^{12}$ and asthmatic subjects who had been shown to be more sensitive to the stimulus $^{13}$ breathed at half this rate. With these levels of ventilation our apparatus generates temperatures of inspired air of $-22^{\circ} \mathrm{C}$ to $-25^{\circ} \mathrm{C}$ for asthmatic subjects and $-18^{\circ} \mathrm{C}$ to $-20^{\circ} \mathrm{C}$ at the higher flow rates of normal subjects. To study the period of refractoriness to cold air, $\mathrm{FEV}_{1}$ and sGaw were determined 40 minutes after the untreated challenge and, provided that these had returned to prechallenge levels, a second challenge was administered and measurements were continued for a further 20 minutes.

Any residual bronchospasm persisting at the end of each session was alleviated by inhaled salbutamol.

Results were anslysed statistically using Student's $t$ test for paired data.

\section{Results}

In normal subjects challenge with cold air at these levels of ventilation produced falls in $\mathrm{FEV}_{1}$ of $6-10 \%$ and in sGaw of $30 \%$. The lowest falls were recorded at 5 and 10 minutes and the response had completely abated by 20 minutes (fig $2 a$ ). Despite the lower levels of ventilation during the challenge, the asthmatic subjects showed larger responses, with mean falls of $20 \%$ in $\mathrm{FEV}_{1}$ and $50 \%$ in sGaw (fig 2). Recovery was less complete at 20 minutes, but by 40 minutes nine of the 12 subjects had returned to prechallenge levels and were able to undergo a repeat challenge. Figure 2 also shows the effects of a repeat
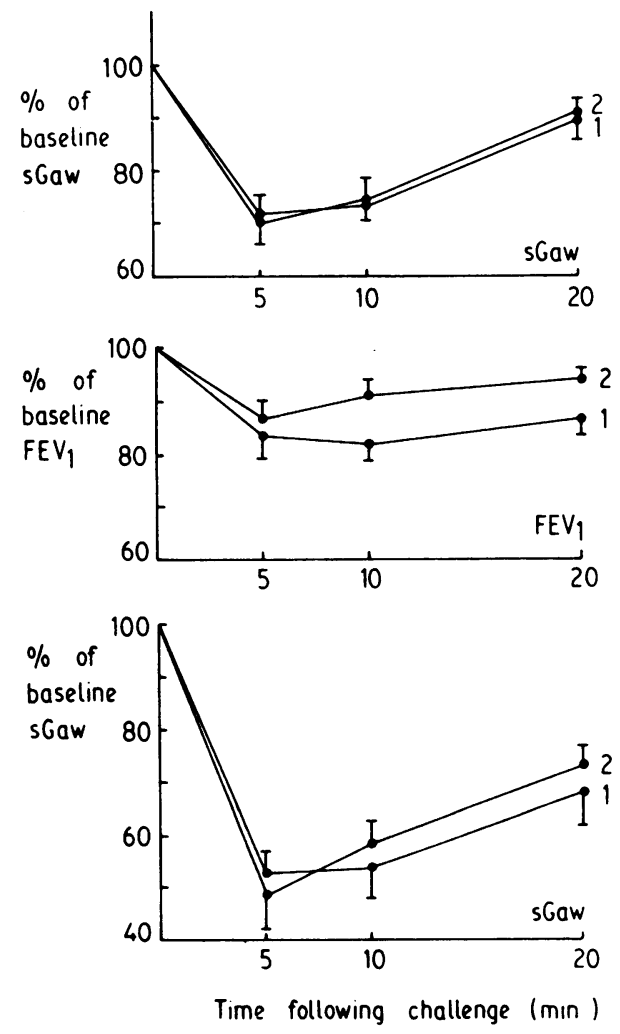

Fig 2 Effect of a repeat cold air challenge (2) administered 40 minutes after an initial challenge (1) in 10 normal subjects $(A)$ and nine asthmatic subjects ( $B$ and $C$ ). sGaw results only are shown for normal subjects as changes in $F E V$, were small. Neither group shows a significant refractory period in terms of sGaw measurements or the maximum fall in $F E V$, after challenge. Values are means \pm $S E$. 

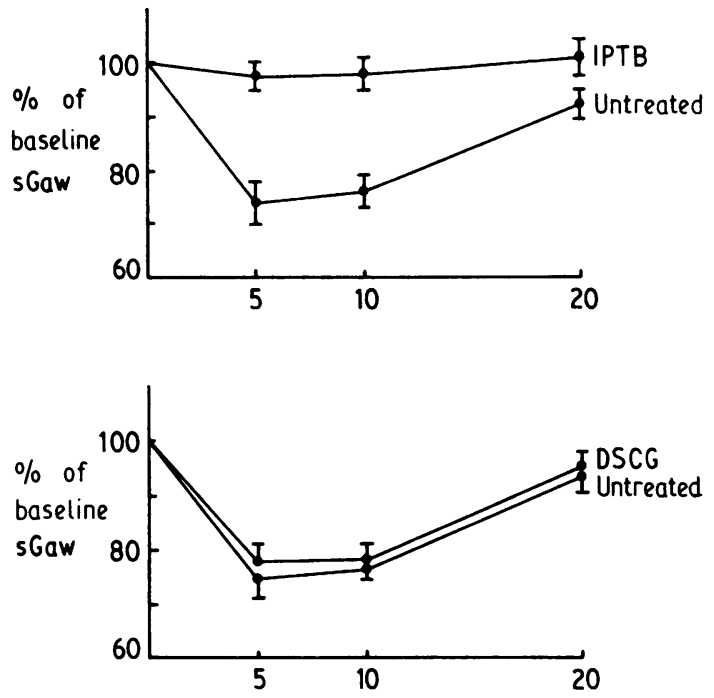

Time following challenge ( $\mathrm{min}$ )

Fig 3 Effect of ipratropium bromide (IPTB) and sodium cromoglycate (DSCG) on the sGaw response in normal subjects. Ipratropium provides significant protection

( $p<0.0005$ at all points) whereas cromoglycate is without effect. Values are means $\pm S E$.

challenge 40 minutes after the initial challenge. Normal subjects show no evidence of a refractory period. Asthmatic subjects also show no refractory period in terms of sGaw measurements or the maximum fall in FEV, after the two challenges (run 1:
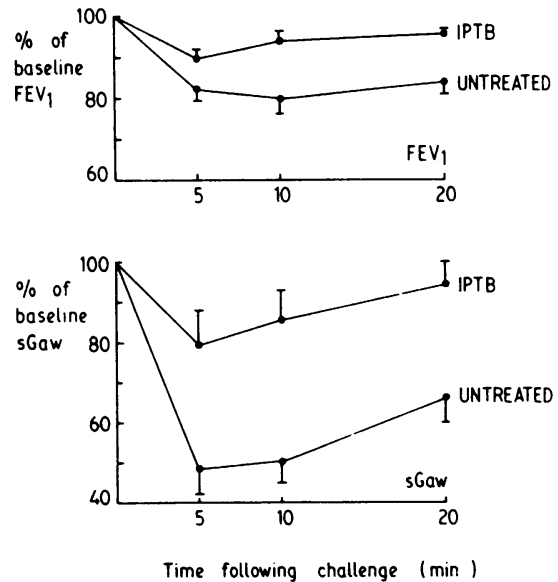

$17.9 \% \pm 3.5 \%$; run $2: 14.6 \% \pm 2.9 \%$ ). The FEV recovers more quickly, however, after the second challenge, and by 20 minutes is significantly higher $(p<0.05)$ than 20 minutes after the first challenge.

In normal subjects the response to airway cooling was completely abolished by ipratropium bromide, whereas sodium cromoglycate was without effect (fig 3). Asthmatic subjects showed a different response to these agents in that both attenuated the response to airway cooling and gave significant protection (fig 4). Ipratropium bromide reduced the maximum fall in sGaw from $57 \cdot 1 \% \pm 4.6 \%$ (mean $\pm \mathrm{SE}$ ) of the baseline values to $21.9 \% \pm 8.4 \%(\mathrm{p}<0.002)$. Sodium cromoglycate reduced the maximum fall to $33.7 \% \pm 5.3 \%$ $(p<0.005)$. Neither agent showed a significant advantage over the other in blocking the response. The two subjects who had never noted wheezing after exercise did not differ in their responses from those who did report exercise-induced wheezing.

\section{Discussion}

Although airway cooling is established as the stimulus to bronchoconstriction in exercise-induced asthma, cooling the airways by eucapnic hyperventilation without exercise does not reproduce all aspects of the response. In the current study we have shown that neither in our normal subjects nor in those with mild asthma was there a period when they were refractory to cold air challenge in terms of the maximum response to the challenge, even though this was repeated at a time when most asth-
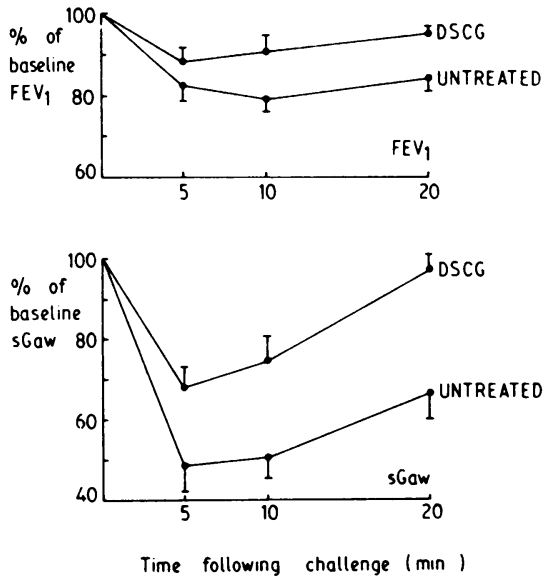

Fig 4 Effect of ipratropium bromide and sodium cromoglycate on the FEV, and sGaw responses in 12 asthmatic subjects. Both agents provided significant protection: ipratropium $\rightarrow p<0.002$ at 10 and 20 minutes for FEV $; p<0.002$ at 5 and 20 minutes and $<0.0005$ at 10 minutes for sGaw; cromoglycate $\longrightarrow p<0.02$ for FEV, and $<0.005$ for sGaw at all points. Values are means $\pm S E$. Abbreviations as in fig 3. 
matics would show a diminished response to repeated exercise challenges. The asthmatics did, how ever, show a less prolonged $F E V_{1}$ response to the second challenge, although the time course of the sGaw response was identical, suggesting that the larger airways were reacting to the stimulus without modification. These results may suggest that the release of preformed mediators has a more important role in exercise-induced asthma than in that produced by eucapnic hyperventilation. This is supported by the findings that histamine ${ }^{14}$ and neutrophil chemotactic factor ${ }^{7}$ rise in the venous blood of asthmatics after exercise challenge, but not after bronchoconstriction induced by hyperventilation alone..$^{14}$ Stearns et al were also unable to demonstrate period of refractoriness in the response to eucapnic hyperventilation in asthmatics who showed a clear period of refractoriness to asthma induced by exercise that produced the same respiratory heat loss, and they suggested that the rise in circulating catecholamines induced by the exercise protected the airways against the repeated challenge. ${ }^{15}$ It has been shown recently, ${ }^{16}$ however, that circulating catecholamines have returned to baseline levels 30 minutes after exercise, at a time when the subjects would still be refractory to further challenge. BenDov et al have recently published evidence to suggest that the refractoriness is related to the exercise itself rather than to airway cooling. ${ }^{17}$

Absence of a period of refractoriness to cold air challenge is consistent with a neural reflex mechanism of bronchoconstriction, and this is supported by the findings of an inhibitory effect with ipratropium bromide. The dose used in this study is not sufficient completely to abolish vagal tone,$^{18}$ although it does increase sGaw in both normal and asthmatic subjects 10 minutes after inhalation. The findings of Barber $e a^{19}$ and our own unpublished observations indicate that there is no further bronchodilatation during the period of these experiments, and thus the protection afforded by ipratropium bromide would appear to be due to blockade of neurally mediated bronchoconstriction, rather than an artefact of increasing bronchodilatation. The smaller responses after ipratropium bromide may reflect the bronchodilatation induced by the ipratropium rather than a specific anticholinergic effect; there was, however, no correlation between the degree of bronchodilatation produced by the ipratropium and the degree of protection afforded. The less complete protection seen in asthmatics may be a reflection of the low dose of ipratropium used and the relatively larger stimulus given to the more sensitive asthmatic airways. Rossing et al have shown that the protection given by $\beta$-sympathomimetic agents can be overcome if the degree of respiratory heat loss is increased. ${ }^{20}$

Additional mechanisms may be operating in asthmatics that are not part of the response of normal subjects. It has been suggested that the size of the response to cold air is a reflection only of bronchial reactivity and that normal subjects differ quantitatively but not qualitatively from asthmatics. ${ }^{21}$ This is not supported by our finding that sodium cromoglycate exerts a protective effect in asthmatics but not in normal subjects, which suggests that the larger response shown by the asthmatics may be due in part to the operation of an additional mechanism which can be blocked by this drug. In studies of exercise-induced asthma sodium cromoglycate has generally been found to be superior to ipratropium bromide in preventing bronchoconstriction, ${ }^{1011}$ whereas in this study there was no significant difference between their effects in asthmatic subjects. As serum levels of mediators rise after exercise-induced asthma, it is perhaps not surprising that cromoglycate is less effective in blocking the response to hyperventilation. Local release of mediators, on a scale too small to affect serum levels, may occur in the asthmatic subjects and contribute to the more intense bronchoconstriction seen in this group.

\section{References}

' Strauss RH, McFadden ER, Ingram RH, Deal EC, Jaegar JJ. Influence of heat and humidity on the airway obstruction induced by exercise in asthma. J Clin Invest 1978;61:433-40.

${ }^{2}$ O'Cain CF, Dowling NB, Slutsky AS, et al. Airways effects of respiratory heat loss in normal subjects. $J$ Appl Physiol 1980;49:875-80.

${ }^{3}$ McFadden ER, Denison DM, Waller JF, Assoufi B, Peacock A, Sopwith T. Direct recordings of the temperatures in the tracheobronchial tree in normal man. $J$ Clin Invest 1982;69:700-5.

${ }^{4}$ Deal EC, McFadden ER, Ingram RH, Strauss RH, Jaegar JJ. Role of respiratory heat exchange in production of exercise induced asthma. J Appl Physiol 1979;46:467-75.

${ }^{5}$ McNeil RS, Nairn JR, Millar JS, Ingram, CG. Exercise induced asthma. $Q J$ Med 1966;35:55-67.

${ }^{6}$ Edmunds AT, Tooley M, Godfrey S. The refractory period after exercise induced asthma: its duration and relation to the severity of exercise. Am Rev Respir Dis 1978;117:247-54.

${ }^{7}$ Lee TH, Nagy L, Nagakura T, Walport MJ, Kay AB Identification and partial characterisation of an exercise induced neutrophil chemotactic factor in bronchial asthma. J Clin Invest 1982;69:889-99.

${ }^{8}$ Nagy L, Lee TH, Kay AB. Neutrophil chemotactic activity in antigen induced late asthmatic reactions. $N$ Engl $J$ Med 1982;306:497-501.

9 Deal EC, Wassermann SI, Soter NA, Ingram RH, McFadden ER. Evaluation of role played by mediators of immediate hypersensitivity in exercise induced asthma. J Clin Invest 1980;65:659-65. 
${ }^{10}$ Thomson NC, Patel HR, Kerr JW. Sodium cromoglycate and ipratropium bromide in exercise induced asthma. Thorax 1978;33:694-9.

${ }^{11}$ Neijens HJ, Wesselius T, Kerrebejn KF. Exercise induced bronchoconstriction as an expression of bronchial hyperactivity: a study of its mechanisms in children. Thorax 1981;36:517-22.

12 Gandevia B, Hugh-Jones P. Terminology for measurements of ventilatory capacity. Thorax 1957;12:290-3.

${ }^{13}$ Deal EC, McFadden ER, Ingram RH, Breslin FJ, Jaegar JJ. Airway responsiveness to cold air and hyperpnoea in normal subjects and in those with hay-fever and asthma. Am Rev Respir Dis 1980;121:621-8.

14 Barnes PJ, Brown MJ. Venous plasma histamines in exercise and hyperventilation induced asthma in man. Clin Sci 1981;61:159-62.

${ }^{15}$ Stearns DR, McFadden ER, Breslin FJ, Ingram RH. Reanalysis of the refractory period in exertional asthma.J Appl Physiol 1981;50:503-8.

${ }^{16}$ Barnes PJ, Brown MJ, Silverman M. Dollery CT. Circulating catecholamines in exercise and hyperventilation induced asthma. Thorax 1981;36:435-40.
${ }_{17}$ Ben-Dov L, Bar-Yashay E, Godfrey S. Refractory period after exercise-induced asthma unexplained by respiratory heat loss. Am Rev Respir Dis 1982;125:530-4.

${ }^{18}$ Douglas NJ, Sudlow MF, Flenley DC. Effect of an inhaled atropine-like agent on normal airway function. J Appl Physiol 1979;46: 256-62.

${ }^{19}$ Barber PV, Chatterjee SS, Scott R. A comparison of ipratropium bromide, deptropine citrate and placebo in asthma and chronic bronchitis. $\mathrm{Br} J$ Dis Chest 1977;71:101-4.

${ }^{20}$ Rossing TH, Weiss JW, Breslin FJ, Ingram RH, McFadden ER. Effects of inhaled sympathomimetics on obstructive response to respiratory heat loss. J Appl Physiol 1982;52:1119-23.

${ }^{21}$ O'Byrne PM, Ryan G, Morris M, et al. Asthma induced by cold air and its relation to non-specific bronchial responsiveness to methacholine. Am Rev Respir Dis 1982;125:281-5.

${ }^{22}$ Heaton RW. Exercise, cold air and asthma. Breath 1982;17:11-4. 